\title{
SUBJETIVIDADE, CORPO E INTERCORPOREIDADE A PARTIR DA FENOMENOLOGIA DE MERLEAU-PONTY
}

M.A. FRANCO ${ }^{1}$, L. A. M. SANTOS ${ }^{2}$, I. DE O. CAMINHA ${ }^{3}$

Universidade de Pernambuco/Universidade Federal da Paraíba ${ }^{1,3}$, Universidade Federal de Sergipe ${ }^{2}$ ORCID ID: https://orcid.org/0000-0002-7468-2302 ${ }^{1}$

macfranco1@gmail.com ${ }^{1}$

Submetido 02/03/2020 - Aceito 14/12/2020

DOI: $10.15628 /$ holos. 2020.9620

\section{RESUMO}

Este artigo é resultado de uma revisão bibliográfica, cujo objetivo foi discutir os conceitos de subjetividade, de corpo e de intercorporeidade a partir da fenomenologia de Maurice Merleau-Ponty. Para este filósofo, o corpo é vivenciado por nós como expressão e realização de nossas intenções, desejos e projetos. É a partir das inúmeras relações que se constitui o processo de construção da subjetividade e suas experiências corporais são caracterizadas como intersubjetividade em ação. Assim posto, faz-se necessário reedificar um mundo simbólico e relacional em torno do corpo humano, que em vez de ser domesticado ou reprimido, estimule a conscientização de um novo contexto social que evite a automatização da vida humana.

PALAVRAS-CHAVE: Fenomenologia. Subjetividade. Corpo. Intercorporeidade.

\section{SUBJECTIVITY, BODY AND INTERCORPOREITY FROM MERLEAU-PONTY'S PHENOMENOLOGY}

\begin{abstract}
This article is the result of a bibliographic review, whose objective was to discuss the concept of subjectivity, the body and intercorporeity from the Phenomenology of Maurice Merleau-Ponty. For this philosopher, the body is experienced by us as an expression and fulfillment of our intentions, desires and projects. It is from the innumerable relationships that the process of building
\end{abstract}

subjectivity is constituted and their bodily experiences are characterized as intersubjectivity in action. Thus, it is necessary to rebuild a symbolic and relational world around the human body, which instead of being domesticated or repressed, stimulates the awareness of a new social context that avoids the automation of human life.

KEYWORDS: Phenomenology. Subjectivity. Body. Intercorporeity. 


\section{INTRODUÇÃO}

Através da corporeidade, todo ser humano entra em contato com o mundo que o cerca e com os outros seres, sendo a partir das inúmeras relações que se constitui o processo de construção da subjetividade. O pensamento de Merleau-Ponty resgata a importância do transbordamento dos sentidos e da percepção. Nessa condição, podemos reconhecer nossa capacidade de sairmos de nós mesmos e entrarmos em contato com os outros, ratificando-se a premissa de que a subjetividade pressupõe a intersubjetividade. Somos um eu e um nós, somos um e múltiplos, simultaneamente, coexistindo de forma intercorpórea com o outro.

Neste estudo, corroboramos com a perspectiva de Surdi, Freire e Mello (2016) que, ao interpretarem o pensamento de Merleau-Ponty, consideram a realização da existência no corpo. Além disso, em nossa interpretação, a subjetividade é compreendida como processo de construção de nossa identidade, de um Eu-Corpo; já a intersubjetividade passa a ser a coexistência de duas ou mais subjetividades, de pessoas em comunicação, que necessitam uma da outra para afirmarem e constituírem-se (seus) corpos-sujeitos, como nos expõe Caminha (2012b).

O corpo vive experiências. Na fenomenologia, isto significa dizer que a experiência é um fenômeno anterior ao próprio indivíduo (Câmara et al. 2016). A partir de como o corpo se situa no mundo, é que podemos pensar como a subjetividade vai se constituindo. Dentro dessa perspectiva, a consciência é concebida como "atitude intencional encarnada em nossa existência corpórea" (Caminha, 2012a, p. 40), ou seja, a subjetividade é inerente ao corpo, é ela que caracteriza o ser humano como humano.

Desse modo, realizamos uma revisão bibliográfica que, segundo Gil (2002), parte da análise de material previamente elaborado, tais como livros e artigos, com o objetivo de discutir o conceito de subjetividade, de corpo e de intercorporeidade a partir da fenomenologia de Maurice MerleauPonty, identificando implicações no contexto sociocultural. As referências que foram utilizadas na revisão foram: Dartigues (1973), Dentz (2008), Matthews (1997) e, em especial, Merleau-Ponty (1991; 1999).

O objetivo deste artigo foi discutir os conceitos de subjetividade, de corpo e de intercorporeidade a partir da fenomenologia de Maurice Merleau-Ponty.

Para estruturarmos nossa discussão, o presente artigo é composto pelos tópicos: corpo próprio em Merleau-Ponty; contribuições da fenomenologia de Merleau-Ponty e as considerações finais.

\section{IDENTIFICANDO AS BASES DOS ESTUDOS DE MERLEAU-PONTY}

Atentando-nos à filosofia, sob a ótica de Merleau-Ponty, certificamo-nos de que ela apresenta o sentido de reaprender a olhar o mundo, e sua fenomenologia representa outra maneira de compreender os fenômenos que nele e com ele ocorrem. 
A saber, para Matthews (2010), as influências sobre Merleau-Ponty partem de Hegel (versão hegeliana do marxismo e da psicologia da forma, gestalt), de filósofos franceses contemporâneos, como Henri Bergson e Gabriel Marcel, além da filosofia ocidental, notadamente, Descartes e Kant. No entanto, o que mais tomou lugar em seu pensamento foi a fenomenologia transcendental de Edmund Husserl (1859-1938) e suas reformulações após as críticas realizadas por seu próprio aluno Martin Heidegger (1889-1976), ao tratar da ontologia, ou seja, o estudo (fenomenológico) do Ser enquanto Ser.

Husserl expõe que a função da fenomenologia estava situada no esclarecimento da essência de conceitos utilizados pela consciência que possuímos do mundo à nossa volta, somado aos das ciências naturais em suas diversas formas. Sendo assim, para tal filósofo, a fenomenologia seria um estudo "transcendental", um recuo quanto ao nosso envolvimento com o mundo (cotidiano e prático) que "investiga pensamentos apenas como pensamentos, sem referência aos objetos desses pensamentos" (Matthews, 2010, p. 20).

Para Heidegger, a fenomenologia deve ser a analítica do dasein (termo que expressa "existência" em alemão ou literalmente "ser/estar aí"), uma análise que busca compreender como as coisas surgem a nós durante nossa existência no mundo (na interação com ele), como percebemos na seguinte afirmação:

Nosso próprio Ser, dizia Heidegger (e nisso foi seguido por Merleau-Ponty), é Ser-no-mundo. (O termo alemão é uma palavra só, inderweltsein que expressa a unidade do conceito que somos forçados a hifenizar em português ou inglês). Não existimos separados do mundo de nossa experiência, somos parte dele. Somos, entretanto, uma parte peculiar do mundo, em virtude de sermos conscientes dele (Matthews, 2010, p. 22).

Reconhecendo as críticas de Heidegger acerca dos fundamentos ontológicos, Husserl atribui à ideia central de sua fenomenologia o lebenswelt, o "mundo vivido". Dessa maneira, o que antes era recuo, agora é aceitação: o envolvimento num mundo. Nesse aspecto, ante a toda teorização, qualquer que seja, esta deve ser situada nesse envolvimento com um mundo, posto que: "A tarefa da fenomenologia era então voltar a esse fundamento subjacente à experiência humana ordinária, que é a fonte da ciência e de todas as outras atividades teóricas" (Matthews, 2010, p. 23).

Ressignificando a redução fenomenológica de Husserl, Merleau-Ponty considera que a subjetividade absoluta, ou mesmo transcendental, é uma contradição por não considerar a experiência vivida como a primeira referência da percepção, a confirmação da existência no corpo situado:

Eu não sou o resultado ou o entrecruzamento de múltiplas causalidades que determinam meu corpo ou meu "psiquismo", eu não posso pensar-me como uma parte do mundo, como o simples objeto da biologia, da psicologia e da sociologia, nem fechar sobre mim o universo da ciência. Tudo aquilo que sei do mundo, mesmo por ciência, eu o sei a partir de uma visão minha ou de uma experiência do mundo sem a qual os símbolos da ciência não poderiam dizer nada (Merleau-Ponty, 1999, p. 3).

Segundo Matthews (2010, p. 27), a fenomenologia, para Merleau-Ponty, consiste "em voltar à pedra basal, à experiência humana direta, pondo de lado quaisquer ideias preconcebidas 
derivadas de nossas teorias científicas ou de filosofias que se apoiam nessas teorias científicas e tentam dar-Ihes um status metafísico".

Nesse sentido, a partir da fenomenologia de Merleau-Ponty, temos a percepção do mundo condizente a cada pessoa e a suas experiências de vida, uma vez que tal filósofo afirma que existem diferentes sujeitos, que cada um tem sua própria experiência do mundo e que não se pode ter consciência de si mesmo apenas por si próprio. Além disso, Matthews (2010) ratifica ainda que nossa subjetividade é formada na relação com o outro e com o mundo. Podemos perceber essa formação nas seguintes palavras:

não posso ter consciência de mim mesmo como sujeito sem também ter consciência de outros sujeitos - "eu" só tem sentido se pode ser contrastado com "você" e outros pronomes pessoais. Aceitar a existência de outros sujeitos tanto quanto de si mesmo é também aceitar que existe um mundo do qual têm experiência todos esses diferentes sujeitos, cada um segundo sua própria perspectiva, mundo esse que fornece o "horizonte" comum para todas as nossas experiências. Portanto, não posso me retirar totalmente para minha própria subjetividade e cortar todos os laços com o mundo do qual tenho consciência. Não estou, enquanto sujeito, fora do tempo e do espaço: sou necessariamente "incarnado" ou "incorporado" em certa situação histórica [...]. Minhas experiências são experiências do mundo e é o mundo que dá sentido às experiências que tenho. Por isso, não posso separar o próprio mundo do mundo enquanto significados para mim: ser humano, segundo Heidegger, é "ser-no-mundo" (Matthews, 2010, 27-28).

No entendimento de Dentz (2008), Merleau-Ponty irá compreender o corpo, qual seja: o corpo-vivido (ou a subjetividade), como um entrelaçamento, uma tensão-dialética. Sobre isso, o autor descreve o corpo-vivido como estrutura dialética em tensão, o que significa dizer que este deve ser entendido a partir de um movimento original de intencionalidade corporal, tendo em vista que: "o corpo não está aberto, mas se abre para o mundo e a este visa como tal; e, em segundo momento, porque vive e experiencia o mundo, ele é transcendência-vivida deste ser-no-mundo" (Dentz, 2008, p. 299).

Essas foram algumas contribuições que Merleau-Ponty recebera para construir seu pensamento sobre o corpo próprio. No tópico seguinte, serão abordados os elementos de sua compreensão propriamente dita acerca da subjetividade, do corpo e da intercorporeidade.

\section{SUBJETIVIDADE, CORPO E INTERCORPOREIDADE}

Na Fenomenologia de Merleau-Ponty (1999), o Corpo assume um significado diferente daquele que encontramos nos manuais das Ciências Biológicas. Portanto, necessário se faz distinguir conceitualmente corpo objeto e corpo próprio ou fenomenal.

A célebre frase: "Mas eu não estou diante de meu corpo, estou em meu corpo, ou, antes, sou meu corpo" (Merleau-Ponty, 1999, p. 207 - 208), representa a compreensão do corpo próprio. É o corpo que nos faz ser essencialmente seres de relação com o mundo e com os outros. Nessa perspectiva, o corpo não é uma coisa nem uma ideia abstrata, ele é presença sensível e intencional, que faz do sujeito perceptivo uma consciência encarnada no mundo, capaz de reaprendê-lo constantemente. 
É por isso que, para Merleau-Ponty (1999), a verdadeira filosofia é reaprender a ver o mundo que realizamos permanentemente. Tal assertiva significa que a subjetividade coincide com os processos corporais; em contrapartida, é preciso considerar que "ser corpo é estar atado a um certo mundo" (Merleau-Ponty, 1999, p. 205). O entendimento do ser-no-mundo é condição necessária para o ser humano voltar-se para si mesmo e organizar seu modo de existir; afinal, somos seres sociais e "possuímos" uma consciência.

Segundo Dartigues (1973), a fenomenologia pretende descrever os fenômenos, e não os explicar ou buscar relações causais; objetiva também investigar as coisas mesmas como elas se manifestam.

"Voltar às coisas mesmas" (Merleau-Ponty, 1999) significa voltar ao mundo da experiência, considerando que, antes da realidade objetiva, há um sujeito que a vivencia e, antes de todo conhecimento, há uma vida que o fundamentou. Exprime que o conhecimento está na origem da experiência que é pré-reflexiva. A visão da essência do fenômeno torna-se possível por uma noção fundamental - o princípio da intencionalidade, tal como explanado por Merleau-Ponty:

A fenomenologia é o estudo das essências, e todos os problemas, segundo ela, resumem-se em definir essências: a essência da percepção, a essência da consciência, por exemplo. Mas a fenomenologia é também uma filosofia que repõe as essências na existência, e não pensa que se pode compreender o homem, o mundo de outra maneira senão a partir de sua "facticidade" (Merleau-Ponty, 1999, p. 1).

A fenomenologia descreve a experiência do homem tal como ela é, e não segundo ss proposições pré-estabelecidas pelas ciências naturais, substituindo as correlações estatísticas pelas descrições individuais, e as conexões causais por interpretações oriundas das experiências vividas, cujos atos, gestos e hábitos refletem um significado. A consciência, mediante a intencionalidade, é compreendida como atribuidora do significado para os objetos. Sem esses significados, não se poderia falar nem de objeto nem de essência do objeto.

O corpo fenomenal é vivenciado por nós como expressão e realização de nossas intenções, desejos e projetos; enquanto que, noutra perspectiva, o corpo objeto é visto como um organismo fisiológico, aquele de que a anatomia e a fisiologia nos falam e do qual nos distanciamos, vendo-o como objeto que obedece a leis físicas e fisiológicas, já que "fragmentado em inúmeras ciências, o corpo passou a ser um objeto submetido ao controle e à manipulação científica" (Gonçalves, 1997, p. 20).

Nesse sentido, percebemos o nosso corpo próprio como um espaço expressivo por possibilitar a comunicação com o mundo e o outro. Somos seres de presença no mundo - um corpo vivido e não meramente um conjunto de órgãos. É pelo corpo que transitamos no mundo e, ao fazermos isso, o corpo se torna "o veículo de ser no mundo..." (Merleau-Ponty, 1999, p. 22). Quando movemos o nosso corpo, é o corpo fenomenal que colocamos em ação, ou seja, o corpo como expressão.

O corpo próprio possui uma intencionalidade pré-reflexiva. Quando queremos pegar algum objeto, atravessar uma rua, abraçar alguém, pular um obstáculo, chutar uma bola, não é necessário 
pensarmos que ações devem ser feitas para resultarem em tais acontecimentos, basta movimentarmos o nosso corpo próprio. Esse engajamento não reflexivo, essa aceitação imediata ao mundo mostra que estamos enraizados numa crença neste mundo na qual não há, em princípio, uma distinção entre pensamento e ato. O corpo é atraído para o objeto. É o gesto de apreensão que torna isso possível. A partir do momento em que o corpo aprende a executar um movimento, não é necessário pensar para realizá-lo:

A consciência é o ser para coisa por intermédio do corpo. Um movimento é apreendido quando o corpo o compreendeu, quer dizer, quando ele o incorporou ao seu mundo, e mover seu corpo é visar às coisas através dele, é deixá-lo corresponder à sua solicitação, que se exerce sobre ele sem nenhuma representação (Merleau-Ponty, 1999, p. 193).

Ao executar um movimento conhecido, o corpo o faz automaticamente, pois tal ação se encontra registrada na memória corporal. O nosso corpo possui o poder de aprender, de incorporar, reformular e jamais esquecer certos hábitos motores como, por exemplo, dançar: para dançar, não é necessário parar e calcular o tempo de cada movimento a ser executado; basta colocar o corpo em ação e o movimento espontaneamente é executado. Todo o nosso corpo, a cada momento, anuncia o nosso sentido e o significado de nossa existência. No exemplo das mãos que se tocam, podemos perceber a capacidade de o corpo tocar e ser tocado, simultaneamente:

Meu corpo, dizia-se, é reconhecível pelo fato de me dar "sensações duplas": quando toco minha mão direita com a esquerda, o objeto mão direita tem esta singular propriedade de sentir, ele também. Vimos há pouco que as duas mãos nunca são ao mesmo tempo tocadas e tocantes uma em relação à outra. Quando pressiono minhas mãos uma contra a outra, não se trata então de duas sensações que eu sentiria em conjunto, como se percebem dois objetos justapostos, mas de uma organização ambígua em que duas mãos podem alternar-se na função de 'tocante' e de 'tocada'. Ao falar de "sensações duplas", queria-se dizer que, na passagem de uma função à outra, posso reconhecer a mão tocada como a mesma que dentro em breve será tocante - neste pacote de ossos e de músculos que minha mão direita é para minha mão esquerda, adivinho em um instante o invólucro ou encarnação desta outra mão direita, ágil e viva, que lanço em direção aos objetos para explorá-los (Merleau-Ponty, 1999, p. 137).

A condição originária e ambígua do corpo é a de pertencer ao mesmo tempo à reflexibilidade e à visibilidade. É um corpo que se conhece sujeito e objeto de forma indivisível. Ao olhar as coisas e o mundo, ele se olha a si, na reversibilidade que lhe é própria, vendo-se vidente. A experiência de ver, sentir e tocar é única e individual. O corpo é possibilidade, visibilidade e reflexibilidade que possui um passado, cujos acontecimentos se encontram registrados na memória corporal e um futuro que o torna sempre aberto ao mundo. Diante disso, é possível afirmar:

A intercorporeidade estabelece relações entre corpos que usam os sentidos não apenas para agir por si só, como também para agir coletivamente. Os corpos vão formando comunidades discursivas de aprendentes. Corpos experimentam o mundo e declaram verdades, que são tomadas como válidas para o grupo social que eles habitam. Corpos reconhecem que outros fazem parte de sua comunidade de convivência. Criamos horizontes de convivências por meio de relações intercorpóreas. Assim, o subjetivo pressupõe o intersubjetivo; o pessoal, o interpessoal; o corporal, o intercorporal. Nossas experiências corporais não são apenas pessoais ou singulares, mas também coletivas ou públicas (Caminha, 2012b, p. 25). 
O corpo, que tanto pode sentir e ser sentido, ver e ser visto, não é apenas objeto nem apenas sujeito; ele está entre os dois e é assim que devemos compreendê-lo: como corpo próprio ou corpo sujeito. Tudo aquilo que enquanto corpo vivemos e pensamos transforma-se em significações. Significação é essencialmente ato comunicativo. Por essa razão:

O corpo é o nosso meio geral de ter um mundo. Ora ele se limita aos gestos necessários à conservação da vida e, correlativamente, põe em torno de nós um mundo biológico; ora brincando com seus primeiros gestos e passando de seu sentido próprio a um sentido figurado, ele manifesta através deles um novo núcleo de significado: é o caso dos hábitos motores, como a dança. Ora enfim a significação visada não pode ser alcançada pelos meios naturais do corpo; é preciso então que ele se construa um instrumento, e ele projeta em torno de si um mundo cultural (Merleau-Ponty, 1999, p. 203).

Dessa forma, podemos compreender que o corpo não age por si só. É através dos movimentos vitais que surge o sujeito e as suas intenções. As suas ações revelam seus significados e constrói o seu comportamento, criando a sua história, a sua cultura perante a sociedade em que vive. Além de atender as suas necessidades vitais, o movimento corporal atende também as suas necessidades sociais; criam-se, então, movimentos simbólicos, isto é, uma linguagem corporal.

O corpo, entendido em sua totalidade, quer dizer, para além da estrutura orgânica, compreende toda uma complexidade que envolve o sentir, o perceber, o pensar e o agir dos indivíduos, revelando a intencionalidade de suas ações - o que caracteriza o homem como um ser repleto de subjetividade.

As vivências por que passam os indivíduos têm significados e sentidos particulares, de acordo com a singularidade subjetiva de cada um. Na perspectiva fenomenológica, a dimensão essencial só apresenta sentido se unida à dimensão existencial, ao mundo vivido. Essência e existência apresentam-se como dimensões de um mesmo fenômeno, o ser humano. Merleau-Ponty admite a perspectiva de corpo objeto, mas reforça a noção de sujeito, enfatizando a possibilidade de criação de sentidos a partir da experiência vivida:

Admitiríamos então que na verdade o corpo, tal como vivemos, parece-nos implicar o mundo, e a palavra, uma paisagem do pensamento. Mas isso seria mera aparência: ante o pensamento sério, meu corpo permaneceria objeto, minha consciência permaneceria consciência pura, e a coexistência de ambos, o objeto de uma apercepção da qual, como pura consciência, eu permaneceria o sujeito (Merleau-Ponty, 1991, p. 99).

Ao criticar as análises tradicionais acerca do corpo, do movimento e da percepção, MerleauPonty enfatiza a experiência corporal fundada numa perspectiva sensível da corporeidade, buscando ultrapassar a dicotomia sujeito/objeto. Dessa maneira, podemos pensar nas contribuições da filosofia de Merleau-Ponty para diversas áreas que compõem o contexto sociocultural, seja a educação, a saúde, a cultura, entre outras. 


\section{CONTRIBUIÇÕES DA FILOSOFIA DE MERLEAU-PONTY}

O entendimento de corpo de Merleau-Ponty ultrapassa a perspectiva do corpo objeto tão divulgada há séculos atrás e ainda hoje existente, chegando a uma concepção de corpo sujeito. Não uma massa inerte, mas um corpo vivo, que sente, pensa e age de maneira própria:

A união entre a alma e o corpo não é selada por um decreto arbitrário entre dois termos exteriores, um objeto, outro sujeito. Ela se realiza a cada instante no movimento da existência. Foi a existência que encontramos no corpo aproximando-nos dele por uma primeira via de acesso, a da fisiologia. Énos permitido então cotejar e precisar este primeiro resultado interrogando agora a existência sobre ela mesma, quer dizer, dirigindo-nos à psicologia (Merleau-Ponty, 1999, p. 131).

Na obra de Merleau-Ponty, a perspectiva do corpo sujeito, como crítica ao modelo estrutural do corpo objeto (fragmento do mundo mecânico), configura-se como a linguagem sensível, confirmando assim as dificuldades do pensamento moderno para traduzir a complexidade dos processos corporais do ser humano, com relação à perspectiva do ser e da experiência dos homens. Por essa razão, afirma que:

O uso que um homem fará de seu corpo é transcendente em relação a esse corpo enquanto ser simplesmente biológico. Gritar na cólera ou abraçar no amor não é mais natural ou menos convencional do que chamar uma mesa de mesa. Os sentimentos e as condutas passionais são inventados, assim como as palavras. Mesmo aqueles sentimentos que, como a paternidade, parecem inscritos no corpo humano são, na realidade, instituições. [...] No homem, tudo é natural e tudo é fabricado, como se quiser, no sentido em que não há uma só palavra, uma só conduta que não deva algo ao ser simplesmente biológico - e que ao mesmo tempo não se furte à simplicidade da vida animal, não desvie as condutas vitais de sua direção, por uma espécie de regulagem e por um gênio do equívoco que poderiam servir para definir o homem. [...] Os comportamentos criam significações que são transcendentes em relação ao dispositivo anatômico, e todavia imanentes ao comportamento enquanto tal, já que este se ensina e se compreende. Não se pode fazer economia desta potência irracional que cria significações e que as comunica. A fala é apenas um caso particular dela (Merleau-Ponty, 1999, p. 257).

Para o corpo, existem significações encarnadas no mundo dado, o que conduz, segundo Merleau-Ponty, à ideia de que a liberdade consiste em pôr-se em situação. Isso aponta para uma análise existencial da relação entre a consciência e a coisa, por intermédio do corpo. $O$ esquema corporal, com efeito, não é simplesmente experiência do corpo, mas experiência do corpo no mundo e, nessa medida, o hábito é fundamental porque renova esse esquema corporal, se posto como apreensão motora de uma significação motora:

O milagre da consciência é fazer aparecer pela atenção fenômenos que restabelecem a unidade do objeto em uma dimensão nova, no momento em que eles a destroem. Assim, a atenção não é nem uma associação de imagens, nem o retorno a si de um pensamento já senhor de seus objetos, mas a constituição ativa de um objeto que explicita e tematiza aquilo que até então só se oferecera como horizonte indeterminado. Ao mesmo tempo em que aciona a atenção, a cada instante o objeto é reaprendido e novamente posto sob sua dependência (Merleau-Ponty, 1999, p. 59). 
Conforme explanado, toda vez que agimos intencionalmente ou executamos uma ação, é a essência da consciência que se manifesta. Nesse sentido, consciência é expansão para o mundo, abrindo-se para uma ligação com aquilo que está perceptível. Mas a consciência não efetua apenas o movimento de expandir-se para o mundo; ela também intenciona e estrutura as próprias vivências. Esse é o movimento pelo qual a consciência abrange as vivências, permitindo visualizálas nitidamente. Refletir, então, passa a ser encarado com um ato e, como tal, sempre passível de tornar-se um evento intencional:

Nosso corpo, enquanto se move a si mesmo, quer dizer, enquanto é inseparável de uma visão de mundo e é esta mesma visão realizada, é a condição de possibilidade, não apenas da síntese geométrica, mas ainda de todas as operações expressivas e de todas as aquisições que constituem o mundo cultural (Merleau-Ponty, 1999, p. 519).

Sendo assim, o agir é permeado de intencionalidade, tornando-se uma característica do sujeito encarnado. É uma atitude assumida perante o mundo e o conhecimento, que tanto é expresso como um conceito estruturante da consciência e é também adotado como modo analítico para justificá-lo. Assim sendo, podemos afirmar que compreender um comportamento é percebêlo, do ponto de vista da intenção que o anuncia, aludindo a fatores que o tornam propriamente humano e o diferenciam de um movimento puramente mecânico.

Se a pessoa desempenha então movimentos voluntários, é por suas intenções, desejos e vontades próprias. A intencionalidade aparece nesse contexto como o que nos permite, de forma imediata, uma interação com o mundo. O corpo é percebido não como instrumento de condutas subjetivas, mas como "sujeito que se constitui em um eu-corporal" (Caminha 2012a, p. 45). Em outras palavras, o corpo é algo inacabado, pois é aberto pela percepção, está sempre interagindo com o mundo, tornando-se o resultado de todo esse processo constitutivo.

Por essa razão, a tarefa da fenomenologia é revelar esse mundo vivido antes de ser significado, mundo em que estamos e vivemos em coexistência com os demais. Um mundo que é o solo de nossos encontros com o outro, em que se descortina nossa história, nossas ações, nosso engajamento, nossas decisões, nossos momentos construtivos. Sendo assim, concluímos que o ponto central da fenomenologia de Merleau-Ponty é a intencionalidade, posta em processo a atitude dela decorrente:

Graças a essa noção ampliada da intencionalidade, a "compreensão" fenomenológica distingue-se da "intelecção" clássica, que se limita às "naturezas verdadeiras e imutáveis", e a fenomenologia pode tornar-se uma fenomenologia da gênese. Quer se trate de uma coisa percebida, de um acontecimento histórico ou de uma doutrina, "compreender" é reapoderar-se da intenção total não apenas aquilo que são para a representação das "propriedades" da coisa percebida, a poeira dos "fatos históricos", as "ideias" introduzidas pela doutrina -, mas a maneira única de existir que se exprime nas propriedades da pedra, do vidro ou do pedaço de cerca, em todos os fatos de uma revolução, em todos os pensamentos de um filósofo (Merleau-Ponty, 1999, p. 16).

Desse modo, a percepção e a intencionalidade unem-se para formar uma integralidade existencial no homem. A formação do sentido compreende a construção do sujeito e a possibilidade de romper com a representação de corpo massificado, padronizado, mecânico e de ações 
repetitivas, destituídas de significação. Surge, então, a necessidade de se voltar para si mesmo, para organizar um modo próprio de existir, a partir das orientações presentes na consciência de cada um. Dessa maneira:

No presente, na percepção, meu ser e minha consciência são um e o mesmo, não que meu ser se reduza ao conhecimento que dele tenho e esteja claramente exposto diante de mim - ao contrário, a percepção é opaca, ela põe em questão, abaixo daquilo que conheço, meus campos sensoriais, minhas cumplicidades primitivas como o mundo -, mas porque aqui "ter consciência" não é senão "ser em..." e porque minha consciência de existir confunde-se com o gesto efetivo de "ex-situação". É comunicando-nos com o mundo que indubitavelmente nos comunicamos com nós mesmos. Nós temos o tempo por inteiro e estamos presentes a nós mesmos porque estamos presentes no mundo (Merleau-Ponty, 1999, p. 569).

Compreendemos, assim, que o pensar fenomenológico de Merleau-Ponty interage, transcende, transporta, mostra, desvela e recobre o mundo para outra dimensão. O sentido de Ser e das coisas se abrem à nossa frente, deixam-se ver, mostram-se. É fundamental entender que o corpo é o resumo do seu contexto social, pois representa elementos específicos como valores, normas e costumes da sociedade em que ele está inserido, e que os gestos executados pelo homem, o modo como se comporta corporalmente, o tipo de atividade que escolhe - tudo é influenciado pelo mundo que o cerca.

Esse entendimento da relação ser-no-mundo nos permite perceber que o ser humano cria, fabrica o mundo e, assim, a si mesmo. No entanto, Caminha (2012b, p. 23) alerta que: "o poder formador de corpos animados que se constituem sujeitos é intersubjetivo". Consoante ele, o ser humano é considerado como existência corpórea e sensível que convive com outros corpos (corpossujeitos) situados no mundo; quanto às nossas experiências corporais, estas são caracterizadas enquanto intersubjetividade em ação, ou seja, são coletivas ou públicas pela razão de nos colocarmos e estarmos situados sempre em contato com alguém. De nossa parte, pensamos que a realidade do homem não deve ser buscada fora das relações sociais.

Portanto, faz-se necessário reedificar um mundo simbólico e relacional em torno do corpo humano que, em vez de ser domesticado ou reprimido, seja estimulado à conscientização de um novo contexto social, pois, provavelmente, agindo dessa maneira, será possível promover vivências diferenciadas que evitem a automatização da vida humana.

Para a constituição da subjetividade, o corpo não está apenas situado no mundo, mas se encontra em constante tensão com ele. Nas palavras de Caminha (2012a, p. 46): "Se vivêssemos num mundo que não oferecesse resistência, não haveria subjetividade. É pela força de agir, movida por intenções, que se esbarra na resistência do mundo, e dessa forma o corpo vai se constituindo um "corpus ego" ${ }^{1}$. Para Caminha (2012b, p. 24), "o corpo se constitui numa subjetividade fundada no poder de sentir e de se movimentar, possibilitando a experiência de saída de si ou de transbordamento", isto é, o corpo por si só desenvolve processos subjetivos, como uma consciência

\footnotetext{
${ }^{1}$ No entendimento de Caminha (2012a, p. 46): “Quando falamos de um sujeito que se constitui por sua motricidade, não queremos dizer que há um ego localizado no corpo, mas que o próprio corpo se estabelece como ego".
} 
encarnada. Justamente por tal motivo, a subjetividade é reconhecida como elemento de construção de nossa identidade, do Eu corpo.

Assim posto, é possível depreender que as ações efetuadas com base na visão ampliada da realidade não são frutos das informações, mas, sobretudo, da relação mantida com o externo (através da observação da própria conduta), da qual se obtém o sentido do lugar preenchido na vida. A intencionalidade abre caminhos para construir e produzir o equilíbrio dos processos de relação, cujo debate sobre o conhecimento abarca, na atualidade, todos os processos naturais e sociais gerados e, a partir daí, são levadas em conta novas formas para interagir.

\section{CONSIDERAÇÕES FINAIS}

Neste estudo, nosso objetivo foi discutir os conceitos de subjetividade, de corpo e de intercorporeidade a partir da Fenomenologia de Maurice Merleau-Ponty. Por meio da revisão, pudemos conhecer as bases dos estudos do filósofo, tendo como fontes os interpretadores de suas obras. Ao nos debruçarmos sobre os conceitos de subjetividade, de corpo e de intercorporeidade, pudemos perceber que o corpo nos faz ser essencialmente seres de relação com o mundo e com os outros.

Em nossa interpretação, uma das principais contribuições da fenomenologia de MerleauPonty encontra-se no argumento de que o corpo não é uma coisa nem uma ideia abstrata, ele é presença sensível e intencional que faz do sujeito perceptivo uma consciência encarnada no mundo capaz de reaprendê-lo constantemente.

O corpo, além de constituir-se biologicamente de propriedades que lhe são inerentes, pode também, a partir delas, projetar-se como um espaço de expressão, de linguagem sensível, capaz de produzir significações diversas, permitindo compreendê-lo também como um fenômeno social e cultural.

A experiência de vivenciarmos, biologicamente e culturalmente, ao mesmo tempo, é proporcionada por nossa corporeidade. O corpo, nesta perspectiva, torna-se espaço de expressão, de identificação, de sensação, de experiências de vida singulares, mas que possuem o outro como uma de suas referências.

\section{REFERÊNCIAS}

Câmara, H. C. et al. (2016). O resgate da subjetividade: diferentes olhares. Holos, 3(32), 305-318.

Caminha, I. de O. (org.). (2012a) Merleau-Ponty em João Pessoa. João Pessoa: Editora Universitária da UFPB.

Caminha, I. de O. (2012b, setembro). O corpo e a experiência de existir enquanto "eu" e "nós". III Colóquio Internacional Corpo e Cultura de Movimento, I Jornada Internacional de Biossistêmica. Anais: Universidade Federal do Rio Grande do Norte - UFRN, Natal, RN, Brasil.

Dartigues, A. (1973) O que é fenomenologia? Rio de Janeiro: Eldorado. 
Dentz, R. A. (2008). Corporeidade e subjetividade em Merleau-Ponty. Instituitio, 1(2), 296-307.

Gil, A. C. (2002). Como elaborar projetos de pesquisa. (4a ed). São Paulo: Atlas.

Gonçalves, M. A. S. (1997). Sentir, pensar e agir: corporeidade e educação. (2a ed, Coleção Corpo e Motricidade). Campinas: Papirus.

Matthews, E. (2010). Compreender Merleau-Ponty. (Tradução: Marcus Penchel). Petrópolis-RJ: Vozes.

Merleau-Ponty, M. (1991). Signos. (Tradução: Maria Ermantina Galvão Gomes Perreira). São Paulo: Martins Fontes.

Merleau-Ponty, M. (1999). Fenomenologia da percepção. (Tradução: Carlos Alberto Ribeiro de Moura). São Paulo: Martins Fontes.

Surdi, A. C., Freire, E. J. S. M., \& Melo, J. P. Corpo e saber sensível: pistas para a educação. Holos, 3(32), 363-370.

\section{COMO CITAR ESTE ARTIGO:}

Franco, M. A., Santos, L. A. M., Caminha, I. de O. (2020). Subjetividade, corpo e intercorporeidade a partir da fenomenologia de Merleau-Ponty. Holos. 36(8), 1-13.

\section{SOBRE OS AUTORES}

\section{M.A. FRANCO}

Possui graduação em Educação Física pela Universidade Federal de Sergipe (2012) e mestrado em Educação Física pela Universidade Federal do Rio Grande do Norte (2017). Atualmente está cursando o doutorado no Programa Associado de Pós-graduação em Educação Física (UPE-UFPB). É professor responsável pelo Projeto de Extensão Iniciação ao Aikido, da UFRN (2015-Atual), foi docente temporário da Escola Multicampi de Ciências Médicas do Rio Grande do Norte (EMCM/UFRN), Coordenador Adjunto do Projeto de Extensão Contato: estudos da anatomia palpatória a partir das práticas integrativas e complementares em saúde (2017), Orientador dos projetos de Práticas Corporais, Bem-estar e Relaxamento (2017) e de Meditação na EMCM (2017). Atua voluntariamente como Terapeuta Integrativo no Lapics (UFRN). Tem experiência na área de Educação Física, atuando principalmente nos seguintes temas: corporeidade, saúde, cuidado de si, práticas corporais e artes marciais.

E-mail: macfranco1@gmail.com

ORCID ID: https://orcid.org/0000-0002-7468-2302

\section{A. M. SANTOS}

Mestre e Doutor em Educação pela Universidade Federal de Sergipe. Professor Associado do Departamento de Educação Física da UFS. Professor do Programa de Pós-Graduação em Educação PPGED/UFS. Coordenador do grupo de pesquisa Formação e Atuação Docente - INTERAÇÃO. Tem experiência na área de Formação Docente, Formação Continuada. Teorias da Aprendizagem, Didática, Filosofia da Educação.

E-mail: luizanselmomenzes@gmail.com

ORCID ID: https://orcid.org/0000-0001-5857-9420

I. DE O. CAMINHA

Graduado em Educação Física pela Universidade Federal da Paraíba (1988). Graduado em Psicologia pelos 
Institutos Paraibanos de Educação (1990). Graduado em Filosofia pela Universidade Federal da Paraíba (1995). Mestre em Filosofia pela Universidade Federal da Paraíba (1996). Doutor em Filosofia pela Université Catholique de Louvain (2001). Atualmente, é professor titular do Departamento de Educação Física, do Programa Associado de Pós-Graduação em Educação Física da Universidade de Pernambuco/Universidade Federal da Paraíba e do Programa de Pós-Graduação em Filosofia da Universidade Federal da Paraíba. Autor dos livros $\mathrm{O}$ distante-próximo e o próximo-distante: corpo e percepção na filosofia de Merleau-Ponty (Editora da UFPB, 2010), Escritos diversos no universo do corpo, educação, psicanálise e filosofia (LiberArs 2015), 10 Lições sobre Merleau-Ponty (Vozes, 2019) e de vários artigos e capítulos de livros sobre Corpo, Educação, Psicanálise e Filosofia.

E-mail: caminhairaquitan@gmail.com

ORCID ID: https://orcid.org/0000-0003-0840-9727

Editor(a) Responsável: Francinaide Nascimento Pareceristas Ad Hoc: Avelino de Lima Neto e Cláudia Battestin

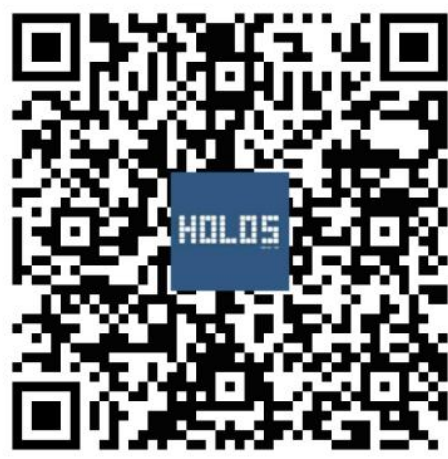

